\title{
A Time-Motion Analysis of Lightweight Women's Judo in the 2010 World Championships
}

\author{
Darren Challis', Adrian Scruton², Michael Cole ${ }^{3}$ \\ and Michael Callan' \\ ${ }^{1}$ Anglia Ruskin University, Sport and Exercise Sciences, Judo Research \\ group, East Road, Cambridge, CB1 1PT. \\ E-mail: bob.challis@anglia.ac.uk. \\ ${ }^{2}$ Anglia Ruskin University, Sport and Exercise Sciences, \\ Sports Research Group \\ ${ }^{3}$ Anglia Ruskin University, Faculty of Science \& Technology
}

\begin{abstract}
The Olympic sport of judo has a growing base of performance analysis research considering the technical aspects, the tactical aspects and time motion analysis. This study aimed to further analyse this sport by specifically considering the time motion aspects of work, rest, kumi-kata and ne-waza in lightweight women's judo to establish if there are differences in this specific population of judo athletes. Pre-recorded footage of the women's u48kg, u52kg and u57kg weight divisions (143 contests) from the 2010 world judo championships were coded into temporal sequences. The coding of five KPls across the three weight groups produced a total of 1756 hajime to matte blocks (work), 1422 matte to hajime blocks (rest), 1786 kumi-kata sequences (gripping sequences), and 516 ne-waza sequences (ground work). The results suggest the time spent in hajime to matte (work) and in matte to hajime (rest) are similar to those seen in other studies. This suggests there is little difference in the work to rest segments for lightweight women's judo compared to heavier weights and males.
\end{abstract}

Key words: Combat Sport, Judo Tactics, Performance Analysis, Sport Analytics

\section{INTRODUCTION}

In 1964 judo became an Olympic sport for men and although it was not included in the following Olympics it has been in every Olympics since 1972. ${ }^{1,2}$ The sportification of judo brought about changes in training methodology, mental preparation, techniques and inevitably with the evolution of contest rules came the evolution of tactics. This was also a period in which the application of science to sports was rapidly increasing, particularly in 
Eastern Europe, China and North Korea. ${ }^{3,4,5}$ These countries used a wealth of sport specific scientific knowledge to develop their judo. Elements such as biomechanics, physiological testing, tactical analysis, psychology, motor learning principles and nutrition were all manipulated.

A major development in judo was the inclusion of women in the 1992 Barcelona Olympic games. Women had the same number of weight categories as men and therefore could yield the same number of medals. They had been included on the 1988 Seoul Olympic Games as a demonstration event. , $^{1,6}$

The major goal of any sports coach is to elicit changes in behaviour that improve performance. This is done via a process often referred to as "the coaching process" where the athlete performs and receives feedback in order to implement changes. ${ }^{7}$ The delivery of this feedback, its objectivity, reliability and the normative values it is measured against have come under much scrutiny ${ }^{8,9}$ and it is now common acceptance that many of the variables can be eliminated by the use of quality performance analysis. ${ }^{10,11}$

Contests for both men and women can be up to five minutes in duration and can include extra time (golden score) of an additional 3 minutes (this has now changed under the 2013 International Judo Federation rules). Developing an understanding of the work to rest ratios and the contribution of different technical components within a contest can assist coaches in developing training methodology that is time effective. While the components of a contest have been studied previously ${ }^{12,13}$ there is little research that focuses solely on women's judo although Van Malderen ${ }^{14}$ did compare time motion data in female and male contests. Therefore this study will focus on women's judo and more specifically lightweight women's judo.

\section{PERFORMANCE ANALYSIS IN JUDO}

Judo has a growing base of performance analysis research. The technical aspects of judo have been studied by many authors. ${ }^{13,15-19}$ The tactical aspects of judo have been studied but are often included within technical analysis research. ${ }^{20-22}$ Time Motion Analysis is not easy to conduct in the sport of judo. However, Miarka, ${ }^{12}$ Sterkowicz ${ }^{13}$ and Marcon ${ }^{23}$ are examples of authors who have conducted research in this area.

Miarka ${ }^{12}$ compared time motion indicators across four age bands in all categories of three regional and one state championships. The key performance indicators were total combat time, pause time, standing combat time, displacement without contact, gripping time and groundwork combat time. The results showed that there was a median of 7 hajime to matte blocks within a contest, this contrasts the findings of other authors who generally found 11-12 hajime to matte blocks. ${ }^{13}, 24-27$ They also showed the average duration of each block by age group, pre-juvenile (21s $\pm 8 \mathrm{~s})$, juvenile (16s $\pm 6 \mathrm{~s})$, junior $(22 \mathrm{~s} \pm 10 \mathrm{~s})$ and senior $(30 \pm 33 \mathrm{~s})$.

The aims of this study were to develop an understanding of the temporal elements of judo specific to lightweight women's judo. In particular work time, rest time, kumi-kata, and ne-waza were considered along side the actual duration of a contest.

\section{METHOD}

Pre-recorded footage of the women's u48kg, u52 kg and u57kg weight divisions (143 contests) from the 2010 world judo championships were coded using sportscode elite performance analysis software (Sportstec, Australia) into temporal sequences of hajime to matte blocks (work blocks). These blocks were then subdivided into kumi-kata (Gripping), attacking/defending and ne-waza (groundwork). Matte to hajime (rest blocks) were also considered. 
A 'coding window' was developed using sportscode elite software (Sportstec, Austrailia) on an imac desktop computer (Apple, US). Figure 1 shows an example of the coding window. Five key performance indicators (KPIs) were established for temporal analysis: Hajime to Matte (work block), Matte to Hajime (rest block), Kumi-kata (gripping phase), attack/defend and transition/ne-waza (ground work).

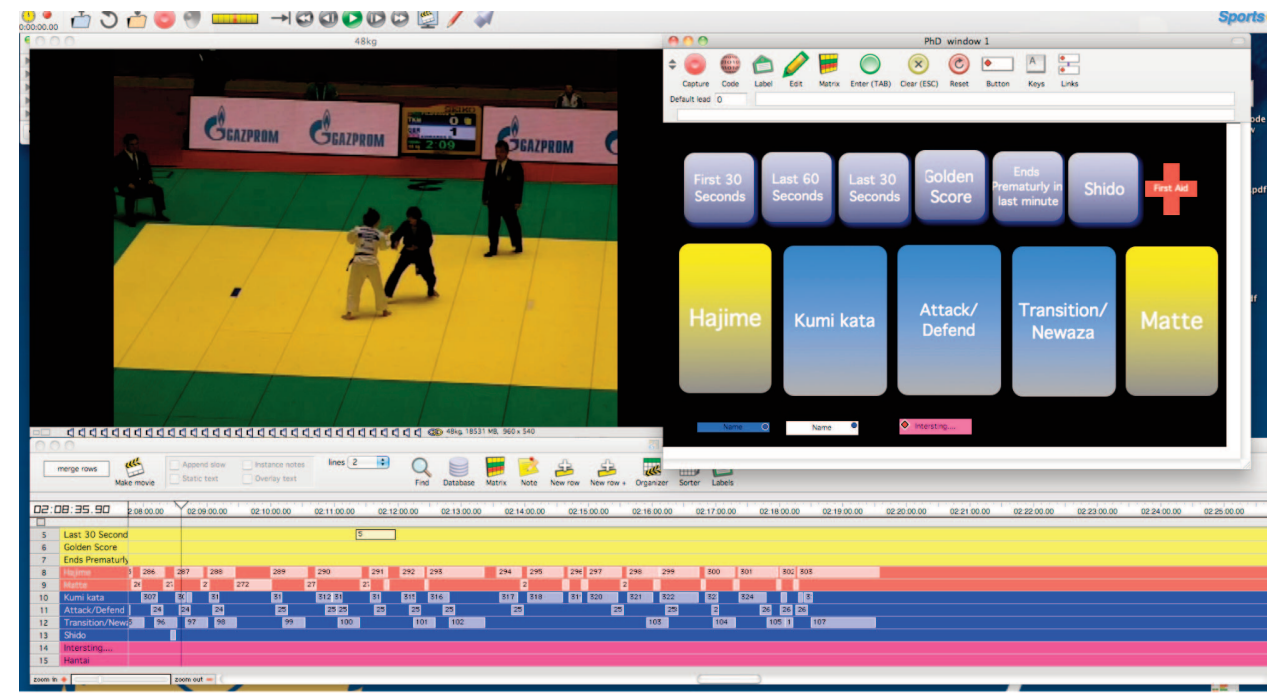

Figure 1. The coding window used for this research alongside the video footage and the sportscode timeline

ETHICS

The Faculty Research Ethics Panel for the Faculty of Science and Technology at Anglia Ruskin University gave ethical approval for this research.

\section{KEY PERFORMANCE INDICATORS}

Hajime to Matte (work periods) - Defined as the period from when the referee says hajime to when the referee says matte.

Matte to Hajime (Rest Periods) - Defined as the period from when the referee says matte to when the referee says hajime. The present study did not observe any instances of "sonomama" or "yoshi" (freeze and restart) but if there had been these would also have been counted as rest periods, this is the same as "pause time" defined by Miarka. ${ }^{12}$

The kumi-kata phase included both lead grip and main grip and therefore started at hajime and ended on the first attack or matte.

Attack/Defend - an action in nage-waza that elicits a score or an attack/control that overcomes a contestant, but is not sufficient enough to be assessed as score, this is normally assessed by the opponent having to react to rebalance themselves. The attack/defend button is used for frequency only, not duration as the researcher needs to see elements prior to and post the attack. 
Transition/Ne-waza - when one or both players have either their knee, front (stomach/chest) or back in contact with the floor and combat continues. Ne-waza included the transitional phase from nage-waza (standing work) and ground work itself

\section{RESULTS}

The coding of five KPIs across the three weight groups produced a total of 1756 hajime to matte blocks (work), 1422 matte to hajime blocks (rest), 1786 kumi-kata sequences (gripping sequences), and 516 ne-waza sequences (ground work). The mean number of occurrences per fight were calculated as shown in Table 1.

Table 1. The number of hajime-matte blocks (Work), Matte-hajime blocks (rest), kumi-kata blocks (gripping), attack/defend sequences and transitions/ne-waze (ground work) for each weight group with the standard deviation

\begin{tabular}{lllll} 
Key Performance indicator & $\mathbf{4 8 k g}(\mathbf{n})$ & $\mathbf{5 2} \mathbf{k g}(\mathbf{n})$ & $\mathbf{5 7} \mathbf{k g}(\mathbf{n})$ & Average across all three weight groups \\
\hline Hajime-matte (work) & $12.7 \pm 7.5$ & $10.3 \pm 6.3$ & $10.1 \pm 7.4$ & $11.0 \pm 7.2$ \\
\hline Matte-hajime (rest) & $11.5 \pm 7.5$ & $9.3 \pm 6.4$ & $9.0 \pm 7.3$ & $9.9 \pm 7.1$ \\
\hline kumi kata (gripping) & $13.5 \pm 8.1$ & $11.7 \pm 7.3$ & $12.3 \pm 8.7$ & $12.5 \pm 8.1$ \\
\hline Attack/Defend & $11.2 \pm 7.0$ & $9.6 \pm 6.0$ & $10.2 \pm 8.2$ & $10.3 \pm 7.1$ \\
\hline Transition/Ne Waza & $4.0 \pm 2.9$ & $3.8 \pm 2.8$ & $3.1 \pm 2.8$ & $3.6 \pm 2.8$
\end{tabular}

After the number of occurrences was established, the time spent in each KPI was calculated. Time spent in each KPI is show in Table 2 and this information gives a more comprehensive understanding of the demands of a contest.

Table 2. The average time (s) and standard deviation for each key performance indicator for each weight group and then the average time for the three weight groups combined.

\begin{tabular}{lllll} 
Key Performance indicator & $\mathbf{4 8 k g}(\mathbf{s})$ & $\mathbf{5 2 k g}(\mathbf{s})$ & $\mathbf{5 7 k g}(\mathbf{s})$ & $\begin{array}{l}\text { Average time in seconds across all three } \\
\text { weight groups }\end{array}$ \\
\hline Hajime-matte (work) & $21.7 \pm 6.8$ & $23.1 \pm 6.5$ & $26.4 \pm 14.3$ & $23.7 \pm 10.0$ \\
\hline matte-hajime (rest) & $8.1 \pm 3.4$ & $8.2 \pm 3.3$ & $8.4 \pm 3.4$ & $8.2 \pm 3.4$ \\
\hline kumi kata (gripping) & $11.7 \pm 4.1$ & $11.4 \pm 3.4$ & $11.4 \pm 5.4$ & $11.5 \pm 4.3$ \\
transition/ne waza & $14.9 \pm 6.6$ & $14.6 \pm 9.2$ & $16.8 \pm 14.4$ & $15.4 \pm 10.6$ \\
\hline
\end{tabular}

A one way ANOVA was used to assess whether there was any significant difference betweengroups for each of the KPI's. No significant differences were found ( $p>0.05)$.

The results show that there was a between-group average a total of $11 \pm 7.2$ hajime to matte blocks (work blocks) of an average duration of $23.7 \mathrm{~s} \pm 10 \mathrm{~s}$ as shown in Figure 1. There are a similar number of matte to hajime blocks (rest blocks), $9.9 \pm 7.1$, but these are much shorter in duration (8.2 seconds on average \pm 3.4 ).

\section{DISCUSSION}

The aims of the present study were to identify the temporal components of a judo contest specific to world class lightweight women in order to establish if there is a need to train or condition these athletes separately. The KPIs used to establish this were developed over a 


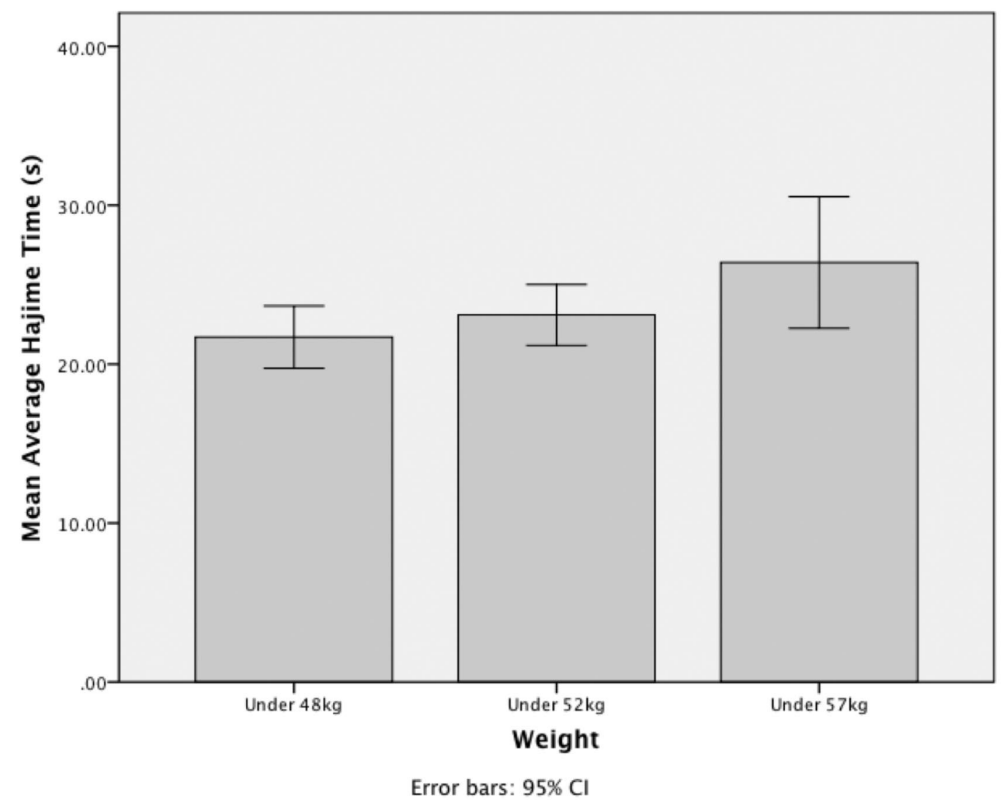

Figure 2. Hajime-matte blocks (time spent in combat) for each weight group. No significant difference was shown between weight groups

period of time using previous research, opinions of performance coaches, opinions of performance analysts from judo and trial and error. Generally the KPIs are similar to those of Miarka ${ }^{12}$ with slight changes in definition, particularly with kumi-kata. The vast majority of information originally expected from coding with these KPIs is available but there are still difficulties with assessing time motion data within the hajime to matte block, such as identifying exact percentages of work/rest time.

Hajime to Matte (work blocks) occur on average 11 times $( \pm 7.2)$ in a contest, this is similar to Casterenas \& Planas $^{24}$ and Sikorski ${ }^{25}$ who presented 11 segments and Sterkowicz ${ }^{13}$ who presented 12 work segments. The average time for hajime to matte demonstrated in this study was $23.7 \pm 10$, this is also similar to Casterenas \& Planas ${ }^{24}$ and Sikorski ${ }^{25}$ who both demonstrated 15-30s hajime to matte segments as well as Franchini ${ }^{28}$ who found 20-30s segments. Miarka ${ }^{12}$ found slightly longer times of 30 s and Sikorski $^{29}$ slight shorter times of $18-25 \mathrm{~s}$ although all of these studies support a hajime to matte time of similar duration.

Matte to hajime (rest blocks) occurred on average 9.9 times per contest $( \pm 7.1)$. Other authors have not clearly described the frequency of matte to hajime segments and have focussed on duration. This study showed that the average time spent in matte to hajime $8.2 \mathrm{~s}$ $\pm 3.4 \mathrm{~s}$. This is supported by the majority of authors $24,13,29$ who found an average of $10 \mathrm{~s}$, Franchini ${ }^{28}$ found $5-10 \mathrm{~s}$ and Miarka ${ }^{12}$ demonstrated an average duration of $11 \mathrm{~s}$.

Total contest time (hajime to matte blocks and matte to hajime blocks) were shown to be 317 seconds (5 minutes 17 seconds). With an average hajime to matte 23.7 seconds and average matte to hajime of 8.2 seconds. This gives a work to rest ratio of 3:1.

The frequency of kumi-kata is slightly higher than that of work segments, averaging 12.5 \pm 8.1 . This is due to some segments having more than one kumi-kata sequence, for example it is possible for a player to attack unsuccessfully and re-engage in kumi-kata. Few studies 
have considered the contribution of kumi-kata within a hajime to matte segment. Calmet et al. ${ }^{30}$ demonstrated that the time spent in hand-gripping to attack varies with the standard of the judoka with less time being spent in kumi-kata by more experienced judoka - beginner $(86 \%)$, intermediate (53\%) and expert (24\%). This indicates that the high-level judoka spend much less time between the grip dominance with two hands and technique application. Miarka $^{12}$ also studied the amount of time spent in kumi-kata, their study considered prejuvenile, juvenile, junior and senior judoka and found the percentage of time spent in kumikata was between 19-30\%. This study did not consider kumi-kata as a percentage of the overall contest, instead time was chosen. Once the physiological demand of kumi-kata is understood, time in seconds will help with the development of judo conditioning. The average time spent in kumi-kata within this study was $11.5 \pm 4.3 \mathrm{~s}$ and no significant difference was seen between the three weight groups.

Attacking and defending was coded only as frequency due to the complexity of establishing duration for such quick and complex actions. Frequency of attacks has not been established in the literature previously and has been show in this study to average 10.3 \pm 7.1 per contest. Multiple attacks in one sequence (renraku-waza and renzoku-waza) were counted as a single attack and possibly accounts for the lower than expected number of attacks. However, understanding the dynamic of the contest follows a structure, hajime, lead grip, main grip, attack/defend, ne-waza, matte would suggest there should be a similar number of attacks as hajime to matte blocks. The slightly lower number being attributed to those hajime to matte blocks where a shido is given before an attack is possible.

$\mathrm{Ne}$-waza/transition only occurred an average of $3.6 \pm 2.8$ times per contest. Although not as frequent as other KPIs, ne-waza did have a long duration (15.4 $\pm 10.6 \mathrm{~s})$ and therefore its contribution to the contest should not be underestimated.

This study was limited by the ability to clearly code actual duration of attacking and defending, this means it was not possible to accurately calculate time in tachi-waza versus time in ne-waza. It is possible to alleviate this issue but coding tachi-waza and ne-waza as separate KPIs.

Further research should investigate the contribution of tachi-waza and ne-waza to a contest. Furthermore a study with more focus on contribution of kumi-kata, attacking/defending should also be considered if possible. Linking this to known physiological demand for each parameter would make programming for strength and conditioning more accurate. More research into the where hands are placed would also be beneficial. A similar study has been undertaken ${ }^{30-32}$, but these need to be completed with a larger sample and under the new rules. All of these parameters should also be studied under the new rules to be implemented for the 2016 Olympic cycle.

\section{CONCLUSION}

This study produced results which corroborate the findings of a great deal of the previous work in this field. However, these data must be interpreted with caution because of different interpretation of KPIs, different software packages and different rules at time of coding. Nevertheless, this consistency suggests there is common ground between researchers and that the temporal components of a contest for lightweight women do not differ from those of other weight groups or men. Furthermore this study has shown work to rest ratios of 3:1 which is in-line with other research ${ }^{24,25,28}$ and therefore it is possible to manage the conditioning of lightweight females in the same way as heavy weight females and males. 


\section{REFERENCES}

1. Brousse, M. and Matsumoto, D.R., Judo: A Sport and a Way of Life, International Judo Federation, 1999.

2. Soames, N. and Inman, R., Olympic Judo: History and Techniques, Ippon Books, Crowood, 1990.

3. Brokhin, Y., The Big Red Machine: The Rise and Fall of Soviet Olympic Champions, Random House, New York, 1978.

4. Riordan, J. and Jones, R.E., ed., Sport and Physical Education in China, Taylor \& Francis, London, 1999.

5. Hardman, K. and Naul, R., ed., Sport and Physical Education in Germany, Routledge, Bodmin, 2002.

6. Inman, R., Judo for Women, Crowood Press, Wiltshire, 1987.

7. Cross, N. and Lyle, J., The Coaching Process. Principles and Practice for Sport, Butterworth \& Heinemann, London, 2001.

8. Hughes, M. and Franks, I., Notational Analysis of Sport: Systems of Better Coaching and Performance in Sport, Psychology Press, London, 2004.

9. Franks, I.M., Goodman, D. and Miller, G., Analysis of Performance: Quantitative or Qualitative, SPORTS, 1993.

10. Hughes, M. and Franks, I.M., ed., The Essentials of Performance Analysis: An Introduction, Routledge, London, 2008.

11. O’Donahue, P., Research Methods for Sports Performance Analysis, Routledge, London, 2009.

12. Miarka, B., Panissa, V., Julio, U., Vecchio, F., Calmet, M. and Franchini, E., A Comparison of Time-Motion Performance Between Age Groups in Judo Matches, Journal of Sports Sciences, 2012, 30(9), 899-905.

13. Sterkowicz, M. and Maslej, P., An Evaluation of the Technical and Tactical Aspects of Judo Matches at the Seniors Level, Division of Combat Sports, Academy of Physical Education, Krakow, Poland, 1999.

14. Van, Malderen, K.V., Jacobs, K., Ramon, C., Evert, K., Deriemaeker, Z. and Clarys, P., Time and Technique Analysis of a Judo Fight: a Comparison Between Males and Females, Annual Congress of the European College of Sports Science, 11, Cologne, 2006.

15. Franchini, E. and Sterkowicz, S., Comparison of Skill Range Between Olympic and World Judo Medalists, in: Annals of the 2nd Express Scientific Conference, Krakow, Poland, 26 June, 1999.

16. Boguszewski, D. and Boguszewska, K., Dynamics of Judo Contests Performed by Finalists of European Championship in Rotterdam 2005, Archives of Budo, 2006, 2, 40-44.

17. Sertic, H., Segedi, I. and Sterkowicz, S., Differences of the Groups of Throws Used by Man and Woman in Different Weight Categories During the European Junior Judo Championships 2005, in: International Association of Judo Researchers (IAJR), Annals of the 5th International Judo Federation World Research Symposium, Rio de Janeiro, Brazil, 12 September 2007.

18. Witkowski, K., Maslinski, J. and Kotwica, T., Analysis of Fighting Actions of Judo Competitors on the Basis of the Men's Tournament During the 2008 Olympic Games in Beijing, Journal of Combat Sports and Martial Arts, 2012, 3(2), 121-129.

19. Sterkowicz, S., Differences in the Specific Movement Activity of Men and Women Practicing Judo, Journal of Human Kinetics, 1999, 1, 99-113.

20. Abdel-Raouf, Y. and Abdelhalem, A., Skillful and Tactical Analysis of the World Judo Senior Championship - Japan 2010 According to the New Amendments of the Regulations, World Journal of Sport Sciences, 2011, 5(3), 188-190.

21. Boguszewski, D., Defensive Actions of World Top Judoists, Journal of Human Kinetics, 2011, 27, 111-122.

22. Franchini, E. and Sterkowicz, S., Techniques Used by Judoists During the World and Olympic Tournaments 1995-1999, Human Movement, 2000, 2(2), 24-332.

23. Marcon, G., Franchini, E., Jardim, J. and Barros Neto, T., Structural Analysis of Action and Time in Sports: Judo, Journal of Quantitative Analysis in Sports, 2010, 6(4).

24. Castarlenas, J. and Planas, A., Study of the Temporal Structure of Judo Combat, Journal of Physical Education and Sports, 1997, 47, 32-39. 
25. Sikorski, W., Mickiewicz, G., Majle, B. and Laska, C., Structure of the Contest and Work Capacity of the Judoist, In Proceedings of the International Congress on Judo "Contemporary Problems of Training and Judo Contest, 1987, 9-11.

26. Challis, D.G., A Temporal Analysis of the u48kg Women's Judo in the 2010 World Championships, 7th International Judo Federation World Judo Research Symposium, Paris, France, 2011.

27. Challis, D.G., A Temporal Analysis of the u52kg Women's Judo in the 2010 World Championships, 8th International Judo Federation World Judo Research Symposium, Rio de Janeiro, Brazil, 2013.

28. Franchini, E., Vecchio, F., Matsushigue, K. and Artiol, G., Physiological Profiles of Elite Judo Athletes, Journal of Sports Medicine, 2011, 41(2), 147-166.

29. Sikorski, W., Identification of Judo Contest from Physiological Viewpoint, Journal of Combat Sports and Martial Arts, 2010, 2(2), 115-118.

30. Calmet, M., Miarka, B. and Franchini, E., Modelling of Grasps in Judo Contests, International Journal of Performance Analysis in Sport, 2010, 10(3), 229-240.

31. Pierantozzi, E., Nerozzi, E., Piras, A. and Lubisco, A., Analysis of the Fighting Phase Before the First Grip in the Finals of the Judo World Championship 2007, Annals of the 1st European Judo Federation Scientific Congress, Lisbon, Portugal, 10th April, 2009.

32. Collins, N. and Challis, D.G., An Analysis of Kumi Kata at the Junior and Senior British Championships 2013, $8^{\text {th }}$ International Judo Federation World Judo Research Symposium, Rio de Janeiro, Brazil, 2013. 